\title{
Do Pathogens from Corneal Scraping Show Their True Colours Better in Bactec Bottles?
}

\author{
LOGESWARY K, HAZLITA MI, WAN HASLINA WAH, THEN KY, \\ AIDA ZMZ
}

Department of Ophthalmology, Faculty of Medicine, Universiti Kebangsaan Malaysia Medical Centre, Jalan Yaacob Latif, Bandar Tun Razak, 56000 Cheras, Kuala Lumpur,

Malaysia.

\begin{abstract}
ABSTRAK
Pengenalpastian jenis organisma dalam kes jangkitan ulser kornea adalah sangat penting supaya rawatan antibiotik yang sesuai dapat diberikan kepada pesakit. Kaedah konvensional dengan menggunakan kultur plat tidak memberi hasil kajian yang memberangsangkan. Percubaan kami dengan teknik yang diubahsuai menggunakan campuran cecair BACTEC untuk mengenal pasti organisma dalam tiga kes jangkitan ulser kornea memberi keputusan cemerlang 100\%.

Kata kunci: medium kultur, kornea, keratitis
\end{abstract}

\begin{abstract}
Identification of causative organisms of clinically suspected microbial keratitis is very important so that appropriate targeted antimicrobial treatment can be offered to patients. The current routine method of corneal scraping specimens on to multiple agar culture plates for microbiological study is not really providing encouraging result. Our trial of modified technique of using BACTEC broth for three clinically suspected microbial keratitis cases worked $100 \%$ to identify the causative organisms in cases of microbial keratitis.
\end{abstract}

Keywords: culture media, cornea, keratitis

Microbial keratitis (infectious keratitis) is a serious sight-threatening ocular infection. Prompt-targeted treatment and subsequent tailoring is needed to check the disease process. This can limit the progression of corneal scarring and severe loss of vision (Thomas \& Geraldine 2007). Identification of the causative organisms and its sensitivity to antibiotics only can be determined

Address for correspondence and reprint requests: Aida Zairani Mohd. Zahidin. Department of Ophthalmology, Faculty of Medicine, Universiti Kebangsaan Malaysia Medical Centre, Jalan Yaacob Latif, Bandar Tun Razak, 56000 Cheras, Kuala Lumpur, Malaysia. Tel: +603-91455981 Fax: +603-9145 6733 E-mail: aidazahidin@gmail.com 
by carrying out microbiological lab test (Wilhelmus \& Schlech 2004). However, even if a specimen of the corneal infiltrate is obtained for microbiological investigation using traditional method, subsequent growth and identification of pathogens occurs only in average of $50.47 \%$ cases (Kratz et al. 2006). The traditional method involves the use of multiple specimens scraping with direct inoculation onto enriched solid culture agar plates (Kaye et al. 2003). Studies were conducted to study the suitability of other transport medium and commercially available broth culture medium to increase positive yields (Kratz et al. 2006; Kaye et al. 2003).

In Universiti Kebangsaan Malaysia Medicla Centre (UKMMC), the routinely performed laboratory investigation for corneal scrape specimen are microscopic examination with gram stain and potassium hydroxide $(\mathrm{KOH})$, followed by inoculation onto conventional culture media like blood, chocolate, MacConkey and sabouraud dextrose agar (Fisher Scientific Sdn Bhd Malaysia, part of Thermo Fisher Scientific). Unfortunately, as reported in the previous study (Kratz et al. 2006), our pathogen recovery from this traditional method is not that encouraging. Thus, we decided to improve culture positive rate for microbial keratitis by adding a new technique using BD BACTEC Peds Plus/F broth (Becton, Dickinson and Company, USA).

Three cases of clinically suspected infectious keratitis in post penetrating keratoplasty eyes, which presented to Ophthalmology Clinic, UKMMC in the month of May 2016 were tested for microbial identification in BD BACTEC Peds Plus/F culture vial. Specimens for the routine microscopic examination of gram stain and potassium hydroxide $(\mathrm{KOH})$; and culture \& sensitivity on culture agar plates (blood, chocolate, Mac'conkey and Sabouraud agar) were taken first then followed by our additional method using corneal scrape specimens into BACTEC vial.

Corneal scrape procedures were carried out under aseptic technique following the instillation of topical anaesthesia (proparacaine hydrochloride $0.5 \%$ ). Sterile surgical blades sized 15 were used for Gramstain, $\mathrm{KOH}$ and conventional culture agar plates (blood, chocolate, MacConkey and sabouraud). Each scraping was carried out with fresh new blade. The base and leading edges of the ulcer was scraped. The scraped material was smeared on two glass slides, one for potassium hydroxide $(\mathrm{KOH})$ wet mount preparation and the other for Gramstain. For, conventional culture method, scrape material was inoculated directly in rows of C-shaped streaks onto room temperature culture plates. For the additional BACTEC method, scraped specimen using 21G sterile needle, which were already connected to $5 \mathrm{ml}$ empty syringe, was used to withdraw and reintroduce liquid broth from and into BACTEC vial (Figure 1 \& Figure 2). All the collected specimens were sent to UKMMC Microbiology laboratory as soon as possible in order to incubate according to standard procedure.

The first case was a specimen from a 7-year-old girl which showed positive growth of Moraxella lacunata in broth and no growth with the culture plate. 


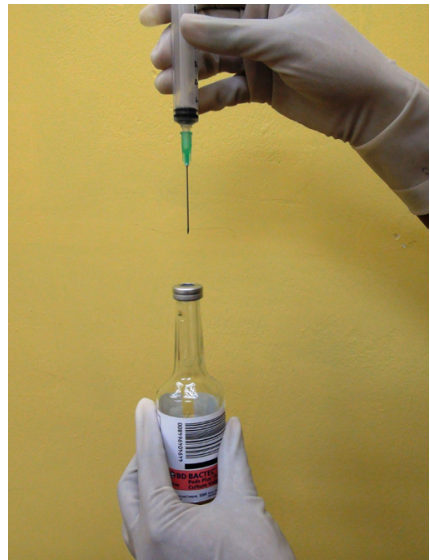

Figure 1: Scraped specimen collected using tip of $21 \mathrm{G}$ sterile needle directly introduced into BACTEC vial.

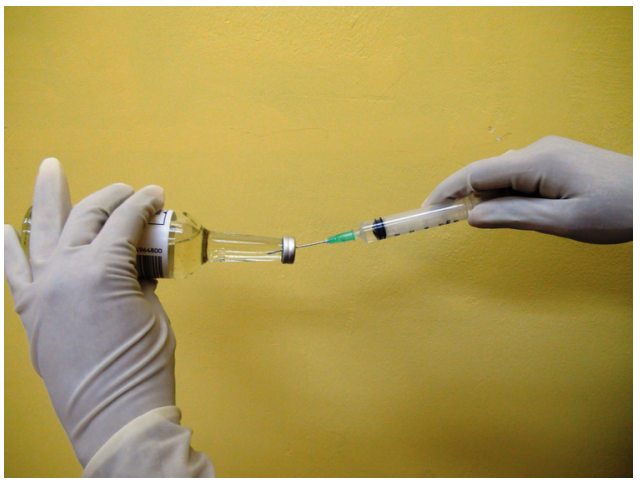

Figure 2: A $5 \mathrm{ml}$ empty sterile syringe connected to $21 \mathrm{G}$ sterile needle used to withdraw and reintroduce liquid broth from and into BACTEC vial.

In the second case involving a 66-yearold lady, both methods yielded positive for Enterobacter spp. Last case from a 56-year-old male eventually yielded only in the broth method and not on culture plates. The organism identified was coagulase negative Staphylococcus (Table 1). We tailored our antibiotic treatment according to culture sensitivity results for all three patients. All three patients eventually recovered without any serious complication such as corneal perforation.
Table 1: The microbial growth outcome in three cases of clinically suspected microbial keratitis.

\begin{tabular}{llc}
\hline & \multicolumn{1}{c}{ BACTEC } & Conventional \\
\hline Case 1 & Moraxella lacunata & - \\
Case 2 & Enterobacter spp & Enterobacter spp \\
Case 3 & Coagulase negative & - \\
& Staphylococcus & - \\
\hline
\end{tabular}

According to the National Eye Survey conducted in 1996, microbial keratitis accounted as the fourth major cause of blindness in Malaysia (Zainal et al. 2002). Identification of causative organisms plays an important role in reducing the morbidity caused by microbial keratitis (Norina et al. 2008). This is because successful targeted treatment can only be given if pathogen is known or else we have to depend on broad spectrum antibiotic which eventually may increase the drug resistance.

Although some keratitis clinically have distinctive appearances, it is not easy to identify the likely causative organisms based on slit lamp examination of the corneal lesion alone. Microbiological laboratory analysis is therefore required for the identification of causative organism (Garg \& Rao 1999). As pathogen recovery is poor through conventional method, considerations need to be taken in order to increase positive culture rate in those analysis by adding new technique.

BD BACTEC Peds Plus/F (Becton, Dickinson and Company, USA) is a type of broth culture medium commonly used in peadiatric practice to isolate microorganisms from small volume sample of about $3 \mathrm{ml}$ blood 
or body fluids (Kratz et al. 2006). The medium contains $20 \mathrm{ml}$ of an enriched soybean-casein digest broth and an optimal amount of sodium polyanethole sulfonate, which enhance the detection of sodium polyanethole sulfonate susceptible organisms. Each vial also contains resins to neutralize antibiotics (Welby et al. 1992). It has been successfully used to recover not only aerobic and anaerobic bacteria but also fungi.

This commercial broth media has been studied in the work-up of microbial keratitis to elucidate whether the BACTEC Peds Plus F could be used for corneal cultures (Kratz et al. 2006). Kratz and associates found this method yields $73.33 \%$ positive cultures combined with conventional method together. In their methodology, specimens were inserted to a regular sterile Eppi 40 tube (Eppendorf International) previously filled with 1.5 $\mathrm{ml}$ of sterile saline $0.9 \%$. The diluted specimen with sterile saline was then drawn using a regular $2.5 \mathrm{ml}$ syringe, and inserted into regular BACTEC Peds Plus $\mathrm{F}$ broth. In our method, BACTEC system was also used, however scraped specimens were directly inoculated into BACTEC vial using sterile needle without diluting it in the sterile saline $0.9 \%$.

As portrayed by these three cases, this modified technique using $B D$ BACTEC Peds Plus/F culture vial to increase positive yields for microbial keratitis at our centre has showed promising results. Thus, in conclusion BACTEC Peds PLUS/F broth can be used successfully as a valuable adjunct to conventional method of agar plates for organisms' identification in the workup of clinically suspected microbial keratitis in our country. Larger sample sized-study using this method may be beneficial in the future.

\section{ACKNOWLEDGEMENT}

The authors thank Mr. Hairul Nizam Harun for image editing.

\section{REFERENCES}

Garg, P., Rao, G.N. 1999. Corneal ulcer: diagnosis and management. Community Eye Health 12(30): 21-3.

Kaye, S.B., Rao, P.G., Smith, G., Scott, J.A., Hoyles, S., Morton, C.E., Willoughby, C., Batterbury, M., Harvey, G. 2003. Simplifying collection of corneal specimens in cases of suspected bacterial keratitis. J Clin Microbio/ 41(7): 3192-7.

Kratz, A., Levy, J., Klemperer, I., Lifshitz, T. 2006. Broth cultures yield vs traditional approach in the workup of infectious keratitis. Eye (Lond) 20(2): 215-20.

Norina, T.J., Raihan, S., Bakiah, S., Ezanee, M., LizaSharmini, A.T., Wan Hazzabah, W.H. 2008. Microbial keratitis: aetiological diagnosis and clinical features in patients admitted to Hospital Universiti Sains Malaysia. Singapore Med J 49(1): 67-71.

Thomas, P.A., Geraldine, P. 2007. Infectious keratitis. Curr Opin Infect Dis 20(2): 129-41.

Welby, P.L., Zusag, T.M., Storch, G.A. 1992. Comparison of the Bactec Peds Plus pediatric blood culture vial with Roche pediatric SeptiChek for blood cultures from pediatric patients. J Clin Microbio/ 30(5): 1361-2.

Wilhelmus, K. R., \& Schlech, B. A. 2004. Clinical and epidemiological advantages of culturing bacterial keratitis. Cornea 23(1); 38-42.

Zainal, M., Ismail, S.M., Ropilah, A.R., Elias, H., Arumugam, G., Alias, D., Fathilah, J., Lim, T.O., Ding, L.M., Goh, P.P. 2002. Prevalence of blindness and low vision in Malaysian population: results from the National Eye Survey 1996. Br J Ophthalmo/ 86(9): 951-6.

Received: 2 December 2016

Accepted: 28 March 2017 